\title{
Fundamentals of Neurophysiology
}


SPRIGER STUD EDITION 


\title{
Fundamentals of Neurophysiology
}

Third, Revised Edition

\author{
Edited by \\ Robert F. Schmidt
}

With Contributions by

J. Dudel W. Jänig R.F. Schmidt

M. Zimmermann

Translated M.A. Biederman-Thorson

With 139 Illustrations

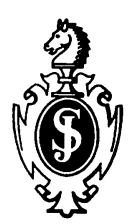

Springer-Verlag

New York Berlin Heidelberg Tokyo 
Robert F. Schmidt

Physiologisches Institut der Universität Kiel, Olshausenstrasse 40/60, 2300

Kiel, Federal Republik of Germany

Josef Dudel

Physiologisches Institut der Technischen Universität München,

Biedersteiner Str. 29, 8000 München 40, Federal Republik of Germany

Wilfrid Jänig

Physiologisches Institut der Universität Kiel, Olshausenstrasse 40/60, 2300

Kiel, Federal Republik of Germany

Manfred Zimmermann

II. Physiologisches Institut der Universität Heidelberg, Im Neuenheimer Feld 326, 6900 Heidelberg, Federal Republik of Germany

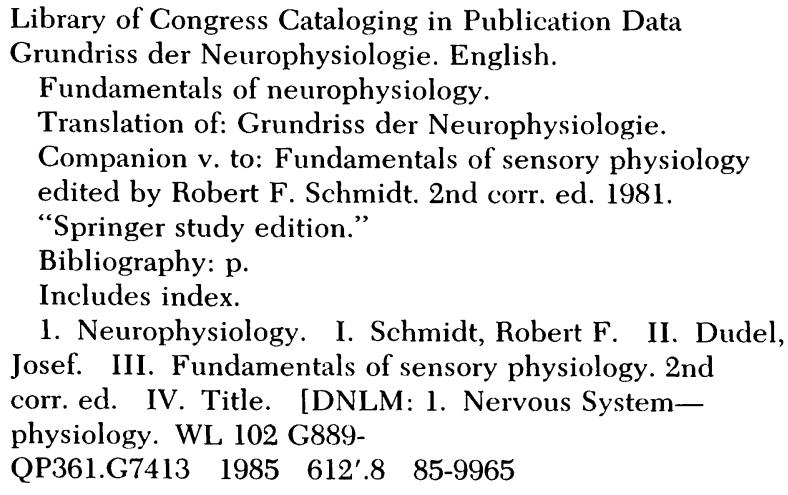

(C) $1975,1978,1985$ by Springer-Verlag New York, Inc.

All rights reserved. No part of this book may be translated or reproduced in any form without written permission from Springer-Verlag, 175 Fifth Avenue, New York, New York 10010 , U.S.A. The use of general descriptive names, trade names, trademarks, etc., in this publication, even if the former are not especially identified, is not to be taken as a sign that such names, as understood by the Trade Marks and Merchandise Marks Act, may accordingly be used freely by anyone.

While the advice and information of this book is believed to be true and accurate at the date of going to press, neither the authors nor the editors nor the publisher can accept any legal responsibility for any errors or omissions that may be made. The publisher makes no warranty, express or implied, with respect to material contained herein.

Typeset by Bi-Comp, Inc., York, Pennsylvania.

98766543321

ISBN-13: 978-0-387-96147-7 e-ISBN-13: 978-1-4613-9553-9

DOI: $10.1007 / 978-1-4613-9553-9$ 


\section{PREFACE TO THE THIRD EDITION}

Again rapid advances in the brain sciences have made it necessary, after only a few years, to issue a revised edition of this text. All the chapters have been reviewed and brought up to date, and some have been largely rewritten. The major revision has occurred in the chapters on the autonomic nervous system and the integrative functions of the central nervous system. But in the discussion of the motor systems and other subjects as well, recent insights have necessitated certain conceptual modifications.

In the description of the autonomic nervous system, the role of the intestinal innervation has been brought out more clearly than before. In addition, there is a new presentation of the physiology of smooth muscle fibers, and more attention has been paid to the postsynaptic adrenergic receptors, because of the increasing therapeutic significance of the $\alpha / \beta$ receptor concept. A substantial section on the genital reflexes in man and woman, including the extragenital changes during copulation, has also been added.

The text on the integrative functions of the central nervous system has been expanded to include, for the first time, material on brain metabolism and blood flow and their dependence on the activity of the brain. Reference is also made to recent results of research on splitbrain and aphasic patients and on memory, as well as on the physiology of sleeping and dreaming.

The list of sources for further reading in this new edition has been made as current as possible; apart from a few "classics" indispensible for an understanding of the development of neurophysiology, most of 
the references cited were published in the last 5 to 10 years. With this list, the reader has immediate access to the original literature.

Many of the illustrations have been improved or replaced, and some new ones added. We are very grateful to Mrs. Renate Lindenbaur, Stuttgart, for her assistance in this task. We also thank the publishers of my book Mediainische Biologie des Menschen, Piper-Verlag in Munich, for permission to reproduce some of its illustrations. The test questions at the end of each section have been retained, with revisions as necessary, to provide the reader with a simple means of checking his progress.

As previously, this book is designed to present both the established background and the most important new results of brain research. The text is concise enough to be absorbed within a reasonable time by nonspecialist students of physiology, whether their primary fields are medicine, psychology, zoology, biology, pharmacology, or other natural sciences. No prior knowledge of anatomy or physiology is assumed; as each term is introduced it is defined and explained in context. The book should therefore be well within the comprehension of anyone studying at the university level. Together with its companion volume, Fundamentals of Sensory Physiology, it provides an extensive introduction to neural and sense-organ function. In particular, we hope the approach, while based on solid fact, will also do justice to the stimulating questions in brain research and to problems still unsolved.

On behalf of all the authors, I again take pleasure in thanking all who have helped to bring this edition into being. We are particularly grateful to Dr. Marguerite A. Biederman-Thorson, Oxford, England, for her excellent translation, to our technical and secretarial colleagues for their tireless efforts, to my wife for her help in compiling the index, and to Springer-Verlag New York, for their close collaboration and painstaking expertise in the production of the book.

Würzburg, Summer 1985

Robert F. Schmidt 


\section{CONTENTS}

Preface to the Third Edition $\ldots \ldots \ldots \ldots \ldots \ldots \ldots$ v

1 The Structure of the Nervous System.

R. F. Schmidt ...................... 1

1.1 The Nerve Cells......................... 1

1.2 Supporting and Nutritive Tissue $\ldots \ldots \ldots \ldots \ldots \ldots .5$

1.3 The Nerves....................... 8

1.4 The Structure of the Spinal Cord ........... 12

2 Excitation of Nerve and Muscle. J. Dudel ......... 19

2.1 Resting Potential .................... 19

2.2 Resting Potential and $\mathrm{Na}^{+}$Influx ............ 27

2.3 The Sodium Pump...................... 32

2.4 The Action Potential . . . . . . . . . . . . . . . . 37

2.5 Kinetics of Excitation.................... 44

2.6 Electrotonus and Stimulus ............... 53

2.7 Propagation of the Action Potential ........... 61

3 Synaptic Transmission. R. F. Schmidt ............ 69

3.1 The Neuromuscular Junction: Example of a

Chemical Synapse ................... 70

3.2 The Quantal Nature of Chemical Transmission ..... 80

3.3 Central Excitatory Synapses . . . . . . . . . . . . . 85

3.4 Central Inhibitory Synapses . . . . . . . . . . . 91

3.5 The Transmitter Substances at Chemical Synapses... 99 
4 The Physiology of Small Groups of Neurons;

Reflexes. R. F. Schmidt .................... 103

4.1 Typical Neuronal Circuits. . . . . . . . . . . . . . . . . . 103

4.2 The Monosynaptic Reflex Arc................ 113

4.3 Polysynaptic Motor Reflexes................. 121

5 Muscles. J. Dudel . . . . . . . . . . . . . . . . . 126

5.1 Contraction of the Muscle............... 126

5.2 Dependence of Force Development on Fiber Length and Velocity of Shortening ................ 135

5.3 Excitation-Contraction Coupling . . . . . . . . . . 143

5.4 Regulation of Muscle Contraction ............... 149

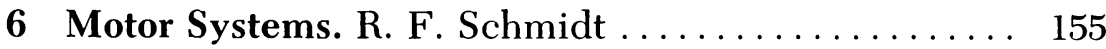

6.1 Spinal Motor Systems I: Roles of Muscle Spindles and Tendon Organs ................. 156

6.2 Spinal Motor Systems II: Polysynaptic Motor. Reflexes; the Flexor Reflex................ 164

6.3 Functional Anatomy of Supraspinal Motor Centers . . 171

6.4 Reflex Control of the Posture of the Body in Space... 182

6.5 Functions of the Basal Ganglia, Cerebellum and Motor Cortex. . . . . . . . . . . . . . . . . . . . . . . . 191

7 Regulatory Functions of the Nervous System, as Exemplified by the Spinal Motor System.

M. Zimmermann ...................... 201

7.1 The Stretch Reflex as a Length-Control System.... . . 202

7.2 Static and Dynamic Properties of Control Systems ... 207

8 The Autonomic Nervous System. W. Jänig. . . . . . . . 216

8.1 Functional Anatomy of the Peripheral Autonomic Nervous System ..................... 216

8.2 Acetylcholine, Noradrenaline and Adrenaline ... . . . 222

8.3 Smooth Muscle: Myogenic Activity and Responses to Stretching, Acetylcholine, and Adrenaline ........ 226

8.4 Antagonistic Effects of Sympathetic and Parasympathetic Activity on Autonomic Effectors ... . 233

8.5 Central Nervous Regulation: Spinal Reflex Arc, Bladder Regulation . . . . . . . . . . . . . . . . . . . . 238

8.6 Genital Reflexes....................... 243 
8.7 Central Nervous Regulation: Arterial Blood Pressure, Regulation of Muscle Perfusion . . . . . . . . . . . . . . 247

8.8 The Hypothalamus. The Regulation of Body

Temperature, Osmolarity of the Extracellular Fluid, and the Endocrine Glands . . . . . . . . . . . . . 252

8.9 Integrative Functions of the Hypothalamus. Limbic System . . . . . . . . . . . . . . . . . . . . . . 262

9 Integrative Functions of the Central Nervous System. R. F. Schmidt . . . . . . . . . . . . . . . 270

9.1 Structure and General Physiology of the Cerebral Cortex; the Electroencephalogram. . . . . . . . . . . 2 271

9.2 Waking, Sleeping, Dreaming . . . . . . . . . . . . 285

9.3 Consciousness and Speech: Structural and Functional Prerequisites . . . . . . . . . . . . . . . . . . . 297

9.4 Learning and Memory.................... 307

9.5 The Frontal Lobes. . . . . . . . . . . . . . . . . . . . . . . . . 314

10 Suggested Readings. . . . . . . . . . . . . . . . . . . . . 317

11 Answer Key . . . . . . . . . . . . . . . . . . . . 323

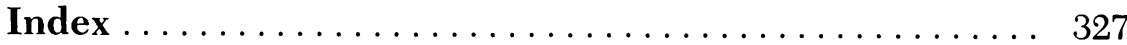

